\title{
Seabirds and fronts: a brief overview
}

\author{
DAVID C. SCHNEIDER
}

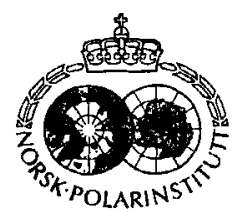

Schneider, D. C. 1990: Seabirds and fronts: a brief overview. Polar Research 8, 17-21.

Oceanographic fronts are the sites of enhanced physical and biological activity, including locally concentrated feeding by marine birds. Two general hypotheses relating marine birds to fronts have been developed. The first is that enhanced primary production at fronts increases prey supply through increased animal growth, reproduction, or immigration. The second is that prey patches develop at fronts either through behavioural responses of prey to thermal or salinity gradients, or through interaction between prey behaviour and circulatory patterns. Several recent studies support the second hypothesis. The first hypothesis, that birds benefit from enhanced primary production at fronts, has yet to be evaluated. We need a better understanding of trophic mechanisms at fronts in order to determine (1) the proportion of daily energy requirements extracted by predators at fronts; (2) the proportion of natural mortality of prey populations at fronts; and (3) the probability of contact between seabirds and point source pollutants.

David C. Schneider, Ocean Sciences Centre, Memorial University of Newfoundland, St. John's, Newfoundland, Canada, A1B 3X7; January 1989 (revised February 1989).

\section{A definition of 'front', with example}

Few people experience any practical difficulty in identifying a front from physical oceanographic data, yet formal definition of the term has proved elusive. Definitions that have been offered (Bowman \& Esias 1978; Holligan 1981; Owen 1981) range from the phenomenological, emphasizing directly measureable quantities, to conceptual, emphasizing dynamic characteristics. The definition that I will use is that of Fedorov (1986): a frontal zone is a region of high spatial gradient in thermodynamic characteristics such as temperature, density, or velocity. A frontal interface is the two-dimensional distribution (surface) having the maximum spatial gradient in some property within this region. A front is the intersection of this surface with any given surface, particularly the free surface of the ocean, or an isopycnal (equal density) surface.

An example will serve to illustrate. Fig. 1 shows the distribution of temperature with depth along a transect beginning $6 \mathrm{~km}$ east of one of the Pribilof Islands, in the southeastern Bering Sea. One can see stratified water near the beginning of the transect, unstratified conditions in slightly shallower water near the end of the transect, and a strong gradient in sea-surface temperature at the transition between these two mixing regimes, near the middle of the transect. The frontal interface, seen from the side, is the line of maximum hori- zontal thermal gradient, which separates mixed and stratified water. The front, seen from the side, is the intersection of this line with the sea
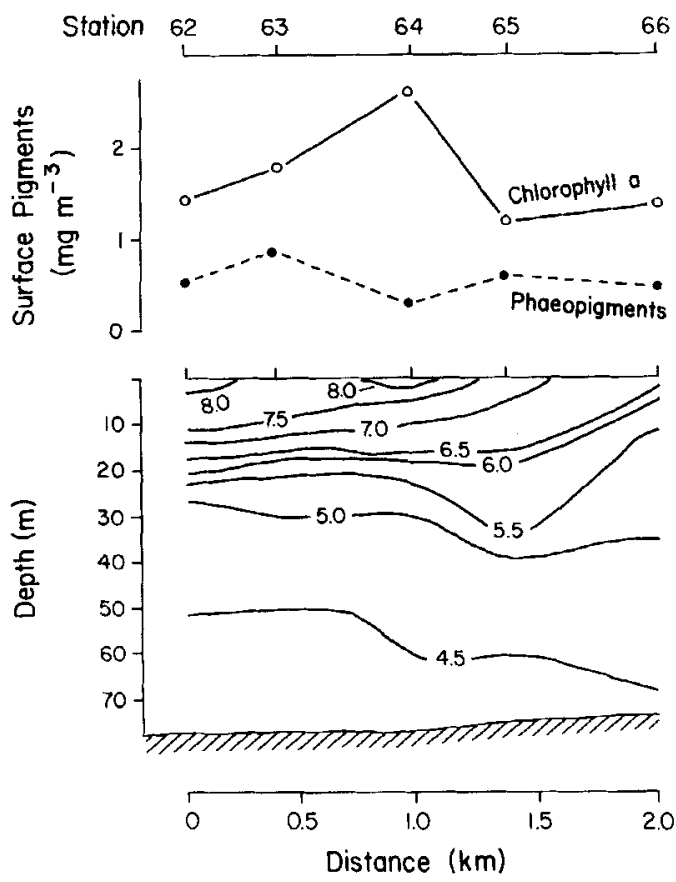

Fig. 1. Thermal structure along a transect running toward $\mathrm{St}$. George lsland, in the southeastern Bering Sea. Profile made on 5 August, 1982 . Profile begins at $56^{\circ} 38.22^{\prime} \mathrm{N}, 169^{\circ} 22.32^{\prime} \mathrm{W}$. Figure taken from Schneider, Harrison \& Hunt (in press). 


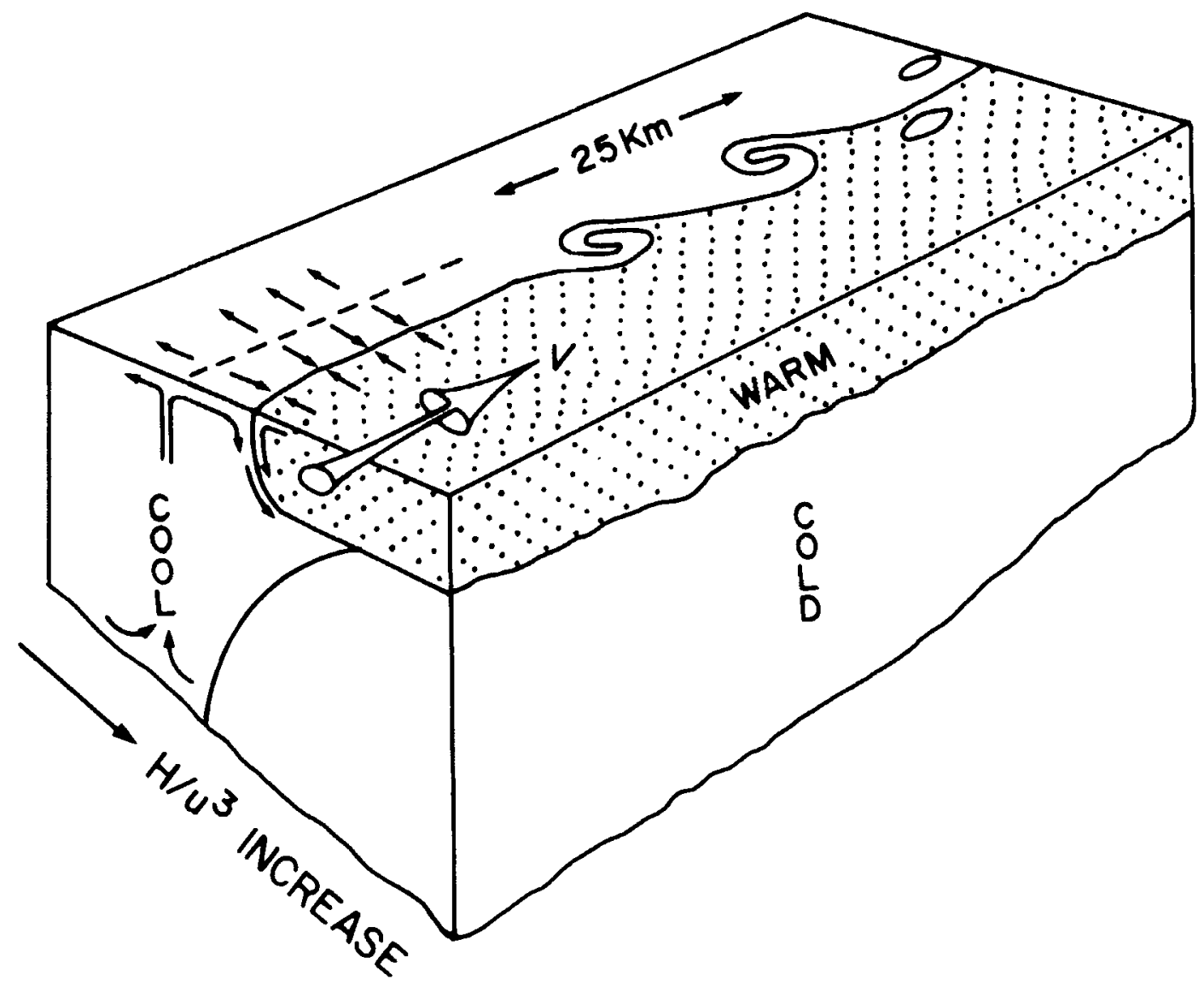

Fig. 2. Interpretation of circulation at front marking the transition from stratified to tidally mixed water. $\mathrm{H} / \mathrm{u}^{3}$ is ratio of water depth to the cube of the tidal stream velocity. Redrawn from Simpson (1981).

surface. This occurs between the $7.5^{\circ} \mathrm{C}$ and $8^{\circ} \mathrm{C}$ isotherms where they intersect the sea surface (Fig. 1). Fig. 2 shows a further interpretation of such a feature, along dynamic lines. Simpson's (1981) interpretation is that of a lateral gradient in the balance between stabilizing (buoyant) and destabilizing (tidal mixing) forces, which result in a rapid shift from mixed to stratified water with a very small change in depth.

\section{Seabird distribution in relation to fronts}

Michitaka Uda, who carried out the pioneering work on fronts ('siome'), reported that seabirds were present in 1 out of 14 crossings of small fronts near Japan (Uda 1938). Despite work on small scale $(<1,000 \mathrm{~km})$ circulatory patterns by Uda and others, the term 'front' did not enter the oceanographic literature until the 1960s. The term does not appear in Bourne's comprehensive review (1963), which discusses several instances of seabird congregation at current boundaries. Subsequent reviews of work on pelagic birds reflect the recent increase in research on birds at fronts, as well as increasingly thorough scouring of older literature for published reports. Brown (1980) listed 8 published reports of birds at fronts. Bourne (1981) listed 8 published works on birds in a 3-paragraph discussion of fronts. By 1985 Hunt \& Schneider (1987) had compiled 20 reports of seabirds at fronts. In early 1986 Brown (in press) tabulated 46 reports of marine birds at fronts inferred from a variety of physical and biological properties. 
Statistical analysis has shown that, in general, fronts explain a significant but relatively small proportion of the observed variation in seabird abundance. In the Bering Sea the presence of a front explains less than $20 \%$ of the observed variability in abundance (Kinder et al. 1983; Schneider, Harrison \& Hunt 1987). In the Southern Ocean Abrams (1985) reported stronger correlation of bird abundance with SST gradients than with other variables, but the variances explained by SST gradients generally fell short of $20 \%$. In the California Current System Briggs et al. (1987) identified SST gradients as the third most important composite variable (after distance from shore and latitude), accounting for less than $20 \%$ of the observed variance in bird abundance.

On a seasonal basis seabird abundance has been correlated with seasonal change in the frequency of surface thermal gradients in shallow waters of the continental shelf east of the Gulf Stream (Haney \& McGillivary 1985). Abundance was not correlated with seasonal frequency of thermal gradients due to eddy formation along the western side of the Gulf Stream (Haney 1986). In the eastern Bering Sea, energy dissipation by pelagic birds was associated with seasonal change in the depth-integrated salinity gradient across the shelf (Schneider, Duffy \& Hunt 1988). On a smaller scale, abundance in frontal zones was not significantly greater than abundance in adjacent waters, but did depend on the strength of the physical gradient, as measured by the inverse of the width of the frontal zone (Schneider, Harrison \& Hunt 1987). Strength of a front, as measured by the inverse of the width of the frontal zone, explained $27 \%$ of the variation in abundance of seabirds in 61 frontal crossings.

One potential source of low explained variance is a mismatch between the spatial scale of the front and the spatial scale at which variability in avian abundance is measured. To test this, Schneider, Pierotti \& Threlfall (in press) measured spatial variability in the abundance of murres Uria aalge and puffins Fratercula arctica along transects across a strong upwelling front in the southern Labrador Current. Variability in abundance was measured at the scale of the first internal Rossby radius, which is the characteristic width of the front between cold upwelled water and adjacent stratified water. The calculated width of the front was confirmed by temperature profiles. During strong upwelling, the front explained less than $15 \%$ of the observed variation in avian abundance. Low explained variance in this case could not be attributed to a mismatch between the scale of the physical phenomenon and the scale of the analysis.

Another potential source of low explained variance is the length of the causal chain linking seabirds to fronts. If the causal link is through prey responses to fronts, then low explained variances can be expected relative to the situation of a direct causal linkage. For example, if fronts explained half of the variation in prey abundance on average, and prey explained half of the variation in avian abundance, then the variance in avian abundance explained by fronts (in the statistical sense) would be $25 \%$. Several recent analyses (Schneider \& Piatt 1986; Hunt, Harrison, \& Cooney in press; Ryan \& Cooper in press; Erikstad this volume) have shown that prey density can explain more than half of the observed variation in avian abundance, often at spatial scales in excess of $5 \mathrm{~km}$. These results suggest that the generally low variance in avian abundance explained by fronts may be due to intermediate levels of association along a 2 step causal chainfronts to prey, and prey to birds.

\section{Feeding at fronts}

Fronts may yet be determinants of spatial variation in prey capture, even though they are not major determinants of distribution. Work on feeding at small frontal features in the Bay of Fundy (Gaskin \& Smith 1979; Brown \& Gaskin 1988) has shown that phalarope feed during the day on copepods found near the sea surface in patches of cool water generated by tidal flow over banks and ledges. These authors attributed this feeding interaction to upward flushing of copepods, which normally migrate downward during the day. Feeding also occurs at convergent areas downstream from ledges, where copepod concentrations occur near the sea surface. Similarly detailed work in the Bering Sea has shown that murres capture euphausiids beneath the surface on the mixed side of a shallow sea front west of the Pribilof Islands (Schneider, Harrison \& Hunt in press). Phalarope (Phalaropus fulicarius) and kittiwakes (Rissa tridactyla) captured injured euphausiids found swimming near the surface at the front. These authors attributed this feeding interaction to subsurface concentration of down- 
ward swimming euphausiids beneath a surface convergence on the mixed side of the front (Simard, de Ladurantaye \& Therriault 1986), upward flushing of euphausiids injured by diving murres, and concentration of injured euphausiids at the convergence associated with the thermal front at the sea surface. Enhanced standing stock of phytoplankton occurs on the stratified side of the front (Fig. 1), while avian predation on euphausiids occurred either at the front (kittiwakes and phalaropes), or on the mixed side of the front (murres). The Bay of Fundy and Pribilof Island studies demonstrate the importance of one of the two hypotheses relating marine birds to fronts, which is that avian predators respond to prey patches that develop through interaction between prey behaviour and circulatory patterns. Detailed work at more locations will be needed to determine whether this generalization applies to other frontal systems. The importance of the alternate general hypothesis, which is that enhanced primary production increases prey supply to birds through enhanced growth, has yet to be evaluated. We do not yet know whether enhanced primary production at fronts is passed along to consumers such as seabirds, or simply carried elsewhere.

Improved understanding of concentrating mechanisms and production processes still falls short of an important goal, which is estimating the magnitude of prey mortality and predator intake in a spatially heterogeneous environment. Both prey mortality and avian intake can be viewed as flux rates upward through the sea surface with dimensions of mass per unit area per unit time $\left(\mathrm{ML}^{-2} \mathrm{~T}^{-1}\right.$ where $\mathrm{M}$ is mass, $\mathrm{L}$ is length, and $T$ is time). Given the area of ocean used by pelagic populations and the difficulty in obtaining 2-dimensional measurements of seabird distribution, some form of interpolation has to be used. One solution is to develop a statistical model of spatial variation in upward flux of prey to avian predators. A wealth of such statistical models exists (Ripley 1981). At present, we cannot expect a statistical model to give us a very precise estimate of flux because of the generally low explained variances reported to date. Another solution, which is standard in physical and biological oceanography, is to construct a dynamic model that captures major features of spatial heterogeneity, such as fronts. The statistical route guarantees an immediate result in any given situation, with no guarantee of carryover to other situations. The alternative route, construction of a model of the feeding dynamics of marine birds in a spatially heterogeneous environment, will take longer, but does hold out the hope of general applicability and greater insight into the sources of spatial variability in trophic interaction between seabirds and their prey.

A better description (and preferably, understanding) of spatial variation in energy flux to marine birds is needed in several contexts. One such context is the impact of changes in the abundance and dispersion of fish and other prey on the foraging success and reproductive output of marine bird populations. How much of a change in either abundance or patchiness of prey must occur, and at what scale, before we can expect a change in foraging success or reproductive output of avian predators? The obverse side of this coin is: can we use seabirds as monitors of change in prey stocks, or are seabirds so loosely coupled with prey as to make them of little practical use in monitoring changes in prey abundance or dispersion? A second important context is improved understanding of natural mortality of commercially important fish species. By tradition, fisheries biologists set natural mortality at $20 \%$ per unit time, a figure that seems to work despite known temporal and spatial variation in rate of prey removal by predators. Can we perhaps use birds as a convenient, highly visible group with which to investigate and attempt to understand spatial variation in natural mortality of commercially important fish stocks? A third important context is the impact of point-source pollutants (notably oilspills) on marine birds. We can be certain that aggregation will decrease the probability of contact between a spill and a group of birds, while increasing the number of encounters, given a contact. To make more specific statements, we need a model of spatial variability in seabird abundance at the spatial scale of oil spills, which range from $10^{0}$ to $10^{10}$ metres in area.

Acknowledgements. - I thank Kjell-Einar Erikstad and his family for their hospitality in Tromsø. Travel to Norway was provided by grants from the Nordic Council and from the Tromse Museum. R.G.B. Brown made several comments that improved the manuscript. This is Ocean Sciences Centre Contribution 33.

\section{References}

Abrams, R. W. 1985: Environmental determinants of pelagic seabird distribution and abundance in the African sector of the Southern Ocean. J. Biogeogr. 12, 473-492. 
Bourne, W. R. P. 1963: A review of occanic studies of the biology of seabirds. Proc. XIII Internat. ornithol. Congr., 831-854.

Bourne, W. R. P. 1981: Some factors underlying the distribution of seabirds. Pp. 119-134 in Cooper, J. (ed.): Proceedings of the Symposium on Birds of the Sea and Shore, 1979. South African Seabird Group, Cape Town.

Bowman, M. \& Esias, W. 1978: Oceanic Fronts in Coastal Processes. Springer-Verlag, Berlin. 114 pp.

Briggs, K. T., Tyler, W. B., Lewis, D. B. \& Carlson, D. R. 1987: Bird communities at sea off California: 1975-1983. Studies in Avian Biology 11, 1-74.

Brown, R. G. B. 1980: Seabirds as marine animals. Pp. 1-49 in Burger, J., Olla, B. L. \& Winn, H. E. (eds.): Behavior of Marine Animals. Plenum Press, New York.

Brown, R. G. B. 1988: Zooplankton patchiness and seabird distributions. Proc. XIX Internat. ornithol. Congr., 10011009.

Brown, R. G. B. \& Gaskin, D. E. 1988: The pelagic ecology of Grey and Red-necked Phalarope Phalaropus fulicarius and $P$. lobatus in the Bay of Fundy, eastern Canada. Ibis 130 , 234-250.

Fedorov, K. N. 1986: The Physical Nature and Structure of Oceanic Fronts. Springer-Verlag, Berlin. 333 pp.

Gaskin, D. E. \& Smith, G. J. D. 1979: Observations on marine mammals, birds and environmental conditions in the Head Harbour region of the Bay of Fundy. Pp. 69-86 in Scarrett, D. J. (ed.): Evaluation of Recent Data Relative to Oil Spills in the Pussamaquoddy Area. Tech. Rep. 901. DFO and Environment Canada, St. Andrews, New Brunswick.

Haney, J. C. 1986: Seabird affinities for Gulf Stream frontal eddies: responses of mobile marine consumers to epjsodic upwelling. J. Mar. Res. 44, 361-384.

Haney, J. C. \& McGillivary, P. A. 1985: Midshelf fronts in the South Atlantic Bight and their influence on seabird distribution and seasonal abundance. Biol. Oceanogr. 3, 401-430.

Holligan, P. M. 1981: Biological implications of fronts on the northwest European continental shelf. Phil. Trans. Roy. Society A302, 547-562.

Hunt, G. L., Jr., Harrison, N. M. \& Cooney, T. in press: Foraging of Least Auklets: The influence of hydrographic structure and prey abundance. Studies in Avian Biology.
Hunt, G. L., Jr. \& Schneider, D. C. 1987; Scale-dependent processes in the physical and biological environment of marine birds. Pp. 7-41 in Croxall, J. (ed.): Seabirds: Feeding Biology and Role in Marine Ecosystems. Cambridge University Press, Cambridge.

Kinder, T. H., Hunt, G. L., Jr., Schneider, D. C. \& Schumacher, J. D. 1983: Correlation between seabirds and oceanic fronts around the Pribilof Islands, Alaska. Estuarine, Coast. Shelf Sci. 16, 309-319.

Owen, R. W. 1981: Fronts and eddies in the sea: mechanisms, interactions and biological effects. Pp. 197-233 in Longhurst, A. R. (ed.): Analysis of Marine Ecosystems. Academic Press, New York.

Ripley, B. D. 1981: Spatial Statistics. Academic Press, London. $252 \mathrm{pp}$.

Ryan, P. G. \& Cooper, J. 1990; The distribution and abundance of seabirds in relation to Antarctic krill in the Prydz Bay region, Antarctica. Polar Biology (in press)

Schneider, D. C., Duffy, D. C. \& Hunt, G. L., Jr. 1988: Crossshelf gradients in the abundance of pelagic birds. Proc. $X I X$ Internat. ornithol. Congr., 976-981.

Schneider, D. C., Harrison, N. M. \& Hunt, G. L., Jr. 1987: Variation in the occurrence of marine birds at fronts in the Bering Sea. Estuarine, Coast. Shelf Sci. 25, 135-141.

Schneider, D. C., Harrison, N. M. \& Hunt, G. L., Jr. in press: Seabird diet at a bathymetric confluence near the Pribilof Islands, Alaska. Studies in Avian Biology.

Schneider, D. C. \& Piatt, J. F. 1986: Scale-dependent correlation of seabirds with schooling fish in a coastal ecosystem. Mar. Ecol.-Progr. Ser. 32, 237-246.

Schneider, D. C., Pierotti, R. \& Threlfall, W, in press: Alcid patchiness and flight direction near a colony in eastern Newfoundland. Studies in Avian Biology.

Simard, Y., de Ladurantaye, R. \& Therriault, J. 1986: Aggregation of euphausiids along a coastal shelf in an upwelling environment. Mar. Ecol.-Progr. Ser. 32, 203-215.

Simpson, J. H. 1981: The shelf-sea fronts: Implications of their existence and behaviour. Phil. Trans. Roy. Soc. Lond. A302, 531-546.

Uda, M. 1938: Researches in 'Siome' or current rip in the sea. Geophys. Magazine 11, 307-372. 
